\title{
CHUTE EXPERIMENTS ON SLUSHFLOW DYNAMICS
}

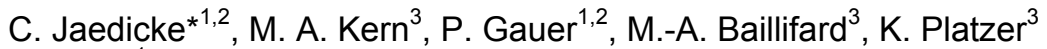 \\ ${ }^{1}$ International Centre for Geohazards, Oslo, Norway \\ ${ }^{2}$ Norwegian Geotechnical Institute, Oslo, Norway \\ ${ }^{3}$ WSL/Swiss Federal Institute for Snow and Avalanche Research, Davos, Switzerland
}

\begin{abstract}
Slushflows are gravity mass flows consisting of a mixture of snow and water, which exhibit considerable damage potential for endangered areas. Small scale slushflows with a volume of $10-15 \mathrm{~m} 3$ were generated in the $30 \mathrm{~m}$ long and $2.5 \mathrm{~m}$ wide snow chute of the Swiss Federal Institute of Snow and Avalanche Research at Weissfluhjoch, Davos, Switzerland. Velocity profiles, dynamic pressure, basal and normal shear and flow height data were recorded in order to test suitable instruments for slushflow measurements. From the obtained data, the order of magnitude of the drag factor for slushflows interacting with obstacles could be estimated. We give an overview of the experimental setup and discuss experimental problems arising from the specific characteristics of slushflows. First results are presented, which indicate that the drag factor might be considerably higher than the estimates commonly used for dry flowing avalanches. Compared to snow avalanches, shear and normal stresses are generally higher in slushflows. The analysis of shear stress versus normal stress indicates some viscoplastic behavior. The results imply that slushflows have to be considered when choosing design criteria for avalanche protection measures wherever this kind of flows can occur. An increase in both temperature and winter precipitation could lead to more frequent slushflow events implying the need to redesign countermeasures. The results from the chute experiments are discussed with respect to development of numerical models of slushflows and a future adaptation of the optical velocity measurement devices to slushflows.
\end{abstract}

KEYWORDS: Slushflow, flow dynamics, scale experiments

\section{INTRODUCTION}

Slushflows are gravity flows consisting of a mixture of water and snow. They are observed globally in areas covered by a seasonal snow cover (Onesti and Hestnes, 1989). Slushflows are released by two different processes, intensive melting in spring time and rain on snow events. Melting dominates in continental climates (Onesti, 1985) while rain on snow is often observed in coastal climate (Hestnes, 1985). Both processes lead to a rapid increase of the water content in the snow cover, such that the water can not drain and accumulates with in the snow cover. The bonds between individual snow crystals are weakened by the presence of free water and the entire snow pack becomes an instable mixture of snow and water.

Slushflows are observed at gentler slopes than avalanches. They can start on terrain with steepness as low as 12 degrees.

\footnotetext{
* Corresponding author address: Norwegian Geotechnical Institute, Oslo, Norway, tel: +47220230 00 email: cj@ngi.no
}

The high density of slushflows and the low internal friction lead to relative high flow velocities associated with highly destructive impact pressures along their paths.

The meteorological conditions necessary for the release of slushflows have been studied extensively both for rain and melt induced releases (Hestnes, et al., 1994, Scherer et al., 1998). The dynamics of the release are difficult to access due to the danger associated with working in the release zones of avalanches. However, Hestnes et al. (1994) give some suggestions on which snow conditions favour the development of slushflows.

The dynamics of the flow is still a open question. Bozhinskiy and Nazarov (1998) presented a model based on the assumption of a two layer flow, where the slush is floating on top of a water layer. However, eye witness observations from slushflow events (Scherer et al., 2001) show a fully turbulent flow. Therefore a new and better model for the flow of slush has to be developed. Gauer (2004) developed a rheology model for slush and tested the approach on a slushflow event in Iceland. $\mathrm{He}$ concluded that field data from the 


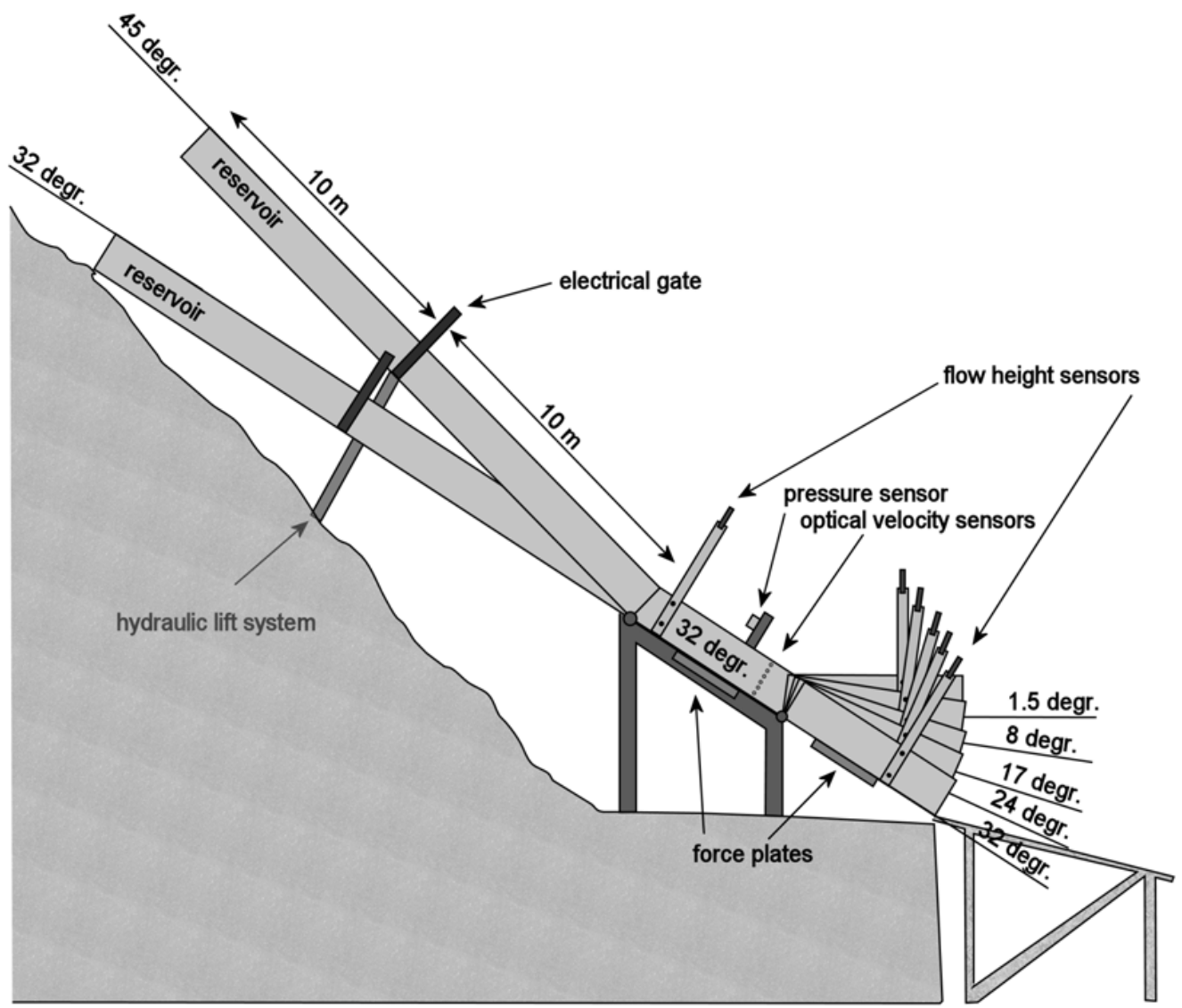

Figure 1: Schematic plot of the SLF chute and its instrumentation

dynamics of the flow are necessary to improve the numerical model.

In this contribution, we present experiments on the dynamics of slushflows which were performed at the Weissfluhjoch snow chute in Davos/Switzerland. The objective of the experiments was to test different measurement devices for slushflow experiments as well as to collect of a primary dataset on the dynamics of slushflows.

\section{THEORETICAL BACKGROUND}

\subsection{Slushflow model}

(Gauer 2003, 2004) proposed a model based on a two-phase multicomponent approach. In this approach, air was considered as continuous gas-phase and the slush as dispersed multi-component "fluid" consisting of snow clods and water. For both phases, the continuity equation and momentum equation were solved. The rheology to describe the dense slush is based on the one of a non-Newtonian fluid with visco-plastic and granular behaviour. To fit the model into the framework of the used numerical flow solver, the stress-strain relationship was written in the following form:

$$
\begin{aligned}
& \mathbf{T}=-p \mathbf{I}+w \mu_{w t r} \mathbf{D}_{s} \\
& +c_{1}\left(\frac{Y_{e}}{2 \sqrt{-\mid I_{\mathbf{D}}}} \mathbf{D}_{s}-p_{c} \mathbf{I}+\mu_{c} \mathbf{D}_{s}\right),
\end{aligned}
$$

where $\boldsymbol{T}$ is the stress tensor, $\boldsymbol{D}_{s}$ is the rate of strain (deformation) tensor of the slush phase, and $I$ is the unit tensor. $I I_{D}(=-$ $\left.1 / 2 \operatorname{tr}\left(\mathbf{D}_{\mathbf{s}}{ }^{2}\right)\right)$ is its second invariant, which is a measure of the effective shear rate. The water content $w=\rho_{s} \theta_{m} / \rho_{w t r}$, is given by the volume fraction of the slush phase and $c_{1}$ is a blending factor to describe the transition from a more snow (granular) to a more water dominated flow regime. The effective viscosity of the water is given by

$$
\mu_{\text {wr }}=\mu_{w} \mathrm{M}_{0}+\mu_{t}
$$

where $\mu_{w}$ is the dynamic viscosity of water, $\boldsymbol{M}_{\boldsymbol{0}}$ is a coefficient, which accounts for the presence of snow particles and $\mu_{t}$ is the turbulent viscosity. The third term on the righthand side in (1) describes the contribution of the snow to the rheology. Here, the first term describes a visco-plastic behaviour, where 


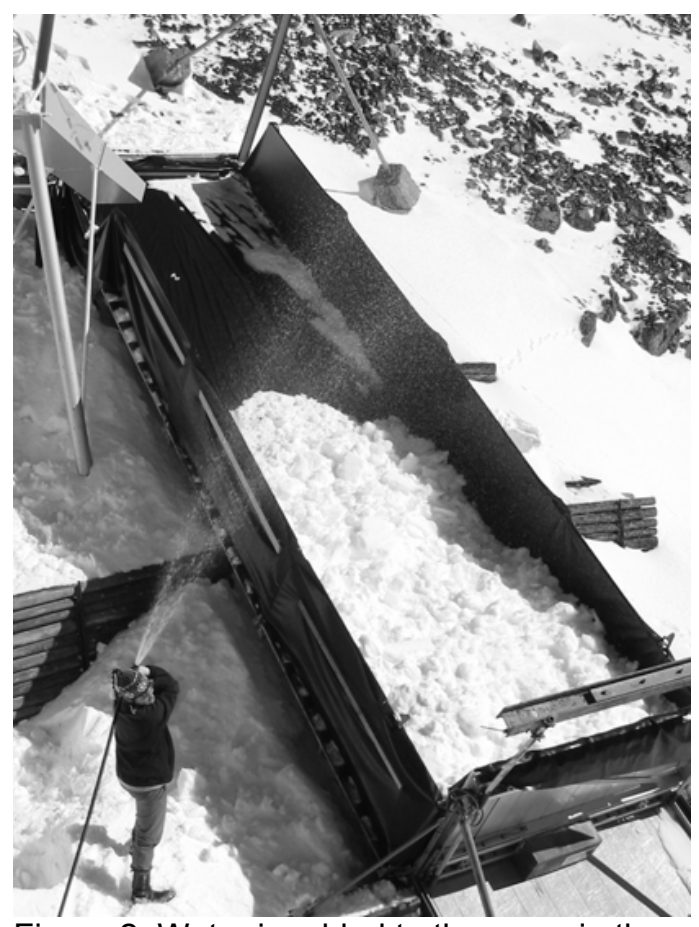

Figure 2: Water is added to the snow in the reservoir. The dike foil ensures that the water is not lost.

the effective yield strength, $Y_{e}$, is assumed to be a function of the density of the dry snowpack and its water content. $p_{c}$ is the collisional pressure and $\mu_{c}$ the collisional viscosity.

Both are assumed to be functions of $I_{D}$ and of the diameter and volume fraction of the snow clods. All terms in (1) involving $D_{s}$ can be combined to an effective viscosity, $\mu_{\text {seff. }}$ The collisional pressure is added to common pressure. The model was implemented within CFX4 (CFX4.3, 1999) and tested for a slushflow event in Iceland.

\subsection{Impact pressure measurements}

The interpretation of load cell measurements is not straightforward. Commonly, the drag force, $F_{D}$, due to a flow around an immersed slender obstacle is expressed in terms of a dimensionless drag factor $C_{D}$, i.e.

$$
F_{D}=C_{D} A_{e} \rho \frac{U_{\infty}^{2}}{2}
$$

Here, $\rho$ is the density of the fluid, $U_{\infty}$ is the upstream flow velocity, and $A_{e}$ is the projected area of the obstacle that is affected. The drag factor itself is a function of the flow regime and depends on factors

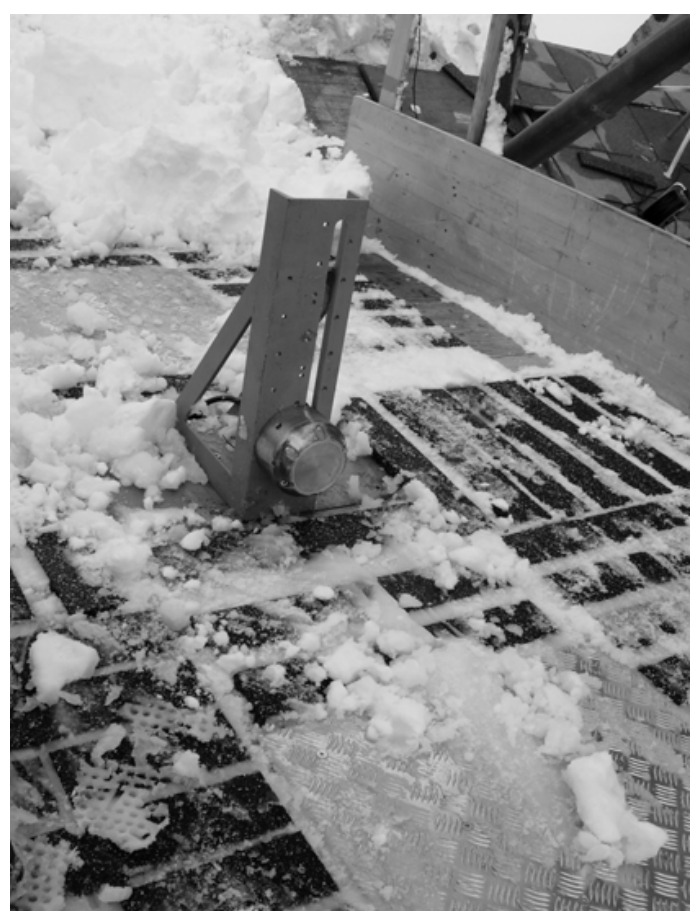

Figure 3: The pressure cell normal to the flow

such as the Reynolds number Re, the Froude number $\mathrm{Fr}$, and the geometry of the obstacle. If one considers a granular flow, $C_{D}$ might also depend on the particle concentration, size, and restitution coefficient of granular particles.

A brief summary on various approaches to define $C_{D}$ values can be found in (Gauer et al, 2006). However, most of the experiments on $C_{D}$ values consider dry snow or dry granular particles, respectively. No investigations are known considering slushflows.

\section{SLUSHFLOW EXPERIMENTS}

\subsection{Experimental setup at Weissflujoch}

The Swiss Federal Institute for Snow and Avalanche Research (SLF) in Davos/Switzerland maintains a test chute for avalanche model experiments (Fig. 1). The SLF chute is located at Weissfluhjoch at $2665 \mathrm{~m}$ asl. The chute is $30 \mathrm{~m}$ long and 2.5 $\mathrm{m}$ wide. It can be tilted to angles between 32 and 45 degrees. The release magazine encompasses up to $25 \mathrm{~m}^{3}$ of snow. During the 2005 experiments, normally $10-15 \mathrm{~m}^{3}$ were used in the experiments due to a seasonal shortage of snow.

The standard instrumentation is set up to measure the basal velocity of the flow at several downstream locations, a velocity 


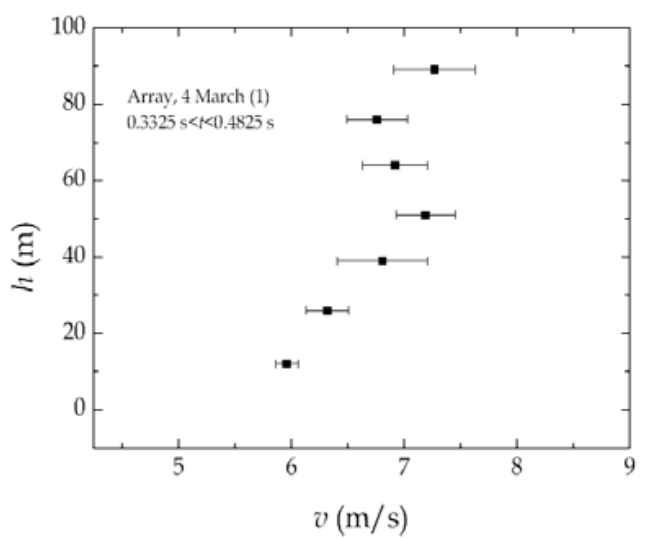

Figure 4: Velocity profile from a snow experiment (4 March 2005, Ex-1)

profile, the flow height and basal stresses on the sliding surface.

All experiments are documented by video and photographs. The instrumentation of the chute is described in detail by Tiefenbacher and Kern (2004).

Slushflow experiments demand a high fraction of water in the snow. Due to leaching, this could not be achieved with the normal setup of the chute at Weissfluhjoch. Therefore a dike foil was installed in the magazine which is $100 \%$ water tight. Water was added with a fire hoarse (Fig. 2)

Additionally to the standard instrumentation, a pressure cell sensor was installed at the centerline in the run out of the chute to measure the direct forces of the avalanche on a pylon in the flow (Fig. 3) during some of the experiments. Similar pressure cells are used at Vallée de la Sionne (Sovilla et al., 2006) test sites to measure the impacts pressures.

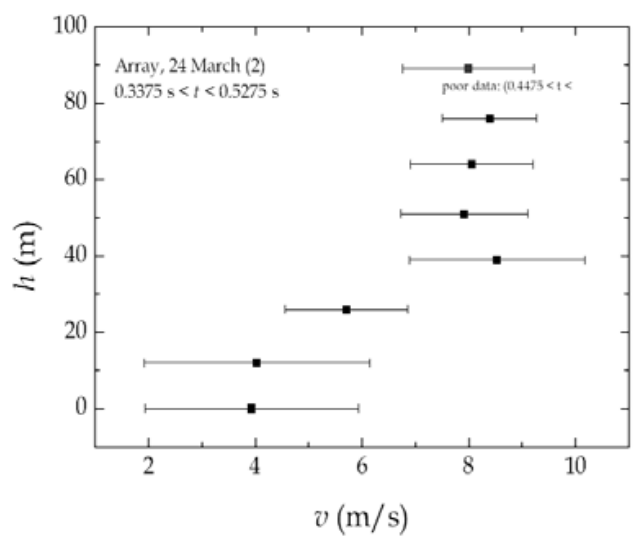

Figure 5: Velocity profile from a slushflow experiment (24 March 2005, Ex-2)

Velocities can be deduced from the pressure measurements if the so called drag factor $\left(C_{D}\right)$ of the flow around the obstacle is known.

During experiments with the force plates and the pressure cell, the velocity measurement array at the centerline of the chute could not be used. Therefore, velocity measurements have to rely on the instruments located at the base (single instruments) and at the walls of the chute (profile).

The slushflow experiments were performed in three groups with different instrumentation:

\section{a) Velocity profile studies}

For the study of the rheology of slush, the velocity profile needs to be studied. For this purpose an optical velocity array, consisting of eight pairs of infrared LED at levels $0-90 \mathrm{~mm}$ over the surface is installed in the centerline of the chute.

Table 2: Key numbers of the 14 slushflow experiments. The snow density $\rho_{\mathrm{s}}$ before release, velocity $V_{\max }$ measured at the side wall of the chute, pressure $P_{\max }$ measured normal to the flow, flow height $H_{\max }$, normal and shear stresses $\mathrm{N}$ and $\mathrm{S}$ at plate 1, 2,3 and 4. All values represent maximum observed values.

\begin{tabular}{|c|c|c|c|c|c|c|c|c|c|c|c|c|c|}
\hline Exp-ID & Angles & Setup & $\begin{array}{c}\rho_{s} \\
{\left[\mathrm{~kg} / \mathrm{m}^{3}\right]}\end{array}$ & $\begin{array}{c}\text { Profiler } \\
V_{\text {max }} \\
{\left[\mathrm{ms}^{-1}\right]}\end{array}$ & $\begin{array}{c}\text { OSM } \\
V_{\max } \\
{\left[\mathrm{ms}^{-1}\right]}\end{array}$ & $\begin{array}{l}P_{\max } \\
{[\mathrm{kPa}]}\end{array}$ & $\begin{array}{c}H_{\max } \\
{[\mathrm{m}]}\end{array}$ & $\begin{array}{l}N_{\text {plate } 2} \\
{\left[\mathrm{Nm}^{-2}\right]}\end{array}$ & $\begin{array}{c}S_{\text {plate } 2} \\
{\left[\mathrm{Nm}^{-2}\right]}\end{array}$ & $\begin{array}{l}N_{\text {plate }} \\
{\left[\mathrm{Nm}^{-2}\right]}\end{array}$ & $\begin{array}{r}S_{\text {plate } 3} \\
{\left[\mathrm{Nm}^{-2}\right]}\end{array}$ & $\begin{array}{l}N_{\text {plate } 4} \\
{\left[\mathrm{Nm}^{-2}\right]}\end{array}$ & $\begin{array}{l}S_{\text {plate }} \\
{\left[\mathrm{Nm}^{-2}\right]}\end{array}$ \\
\hline 180305-No-01 & $32-32-32$ & $\begin{array}{l}\text { Velocity } \\
\text { profile }\end{array}$ & 582 & 11.2 & 5.5 & - & 0.68 & 2000 & 800 & - & - & - & - \\
\hline \begin{tabular}{|l|}
$180305-N o-02$ \\
\end{tabular} & \begin{tabular}{|l|}
$32-32-32$ \\
\end{tabular} & Failure of dat & acquisiti & & & & & & & & & & \\
\hline 240305-No-01 & \begin{tabular}{|l|}
$32-32-32$ \\
\end{tabular} & $\begin{array}{l}\text { Velocity } \\
\text { profile }\end{array}$ & 634 & 12.9 & 11.7 & - & 0.68 & 1240 & 400 & - & - & - & - \\
\hline 240305-No-02 & \begin{tabular}{|l|}
$32-32-32$ \\
\end{tabular} & $\begin{array}{l}\text { Velocity } \\
\text { profile }\end{array}$ & 661 & 10.7 & 8.2 & - & 0.75 & 1200 & 550 & - & - & - & - \\
\hline 010405-No-01 & $32-32-32$ & $\begin{array}{l}\text { Velocity } \\
\text { profile }\end{array}$ & 634 & 12.8 & 10.7 & - & 0.78 & - & - & - & - & - & - \\
\hline \begin{tabular}{|c|}
$010405-N o-02$ \\
\end{tabular} & \begin{tabular}{|l|}
$32-32-32$ \\
\end{tabular} & $\begin{array}{l}\text { Velocity } \\
\text { profile }\end{array}$ & 687 & 10.2 & 11.5 & - & 0.79 & - & - & - & - & - & - \\
\hline $120405-\mathrm{No}-04$ & \begin{tabular}{|l}
$32-32-1.5$ \\
\end{tabular} & Galleries & 750 & - & 6.2 & - & 0.95 & & & 2898 & 834 & 7572 & 4348 \\
\hline \begin{tabular}{|c|}
$130405-\mathrm{No}-04$ \\
\end{tabular} & $32-32-8$ & \begin{tabular}{|l} 
Galleries \\
\end{tabular} & 643 & - & 8.6 & - & 0.90 & & & 3779 & 937 & 7113 & 3132 \\
\hline 140405-No-02 & \begin{tabular}{|l|}
$32-32-17$ \\
\end{tabular} & Galleries & 715 & - & 9.2 & - & 1.01 & & & 3413 & 1120 & 4657 & 2833 \\
\hline \begin{tabular}{|c|}
$150405-\mathrm{No}-02$ \\
\end{tabular} & $32-32-24$ & $\begin{array}{l}\text { Galleries } \\
\end{array}$ & 714 & - & 9.0 & - & 0.72 & & & 5932 & 971 & 4495 & 1454 \\
\hline \begin{tabular}{|c|}
$180405-N o-01$ \\
\end{tabular} & $32-32-32$ & \begin{tabular}{|l|} 
Pressure cell \\
\end{tabular} & 476 & & 7.3 & 42 & 1.01 & & & & & & \\
\hline
\end{tabular}




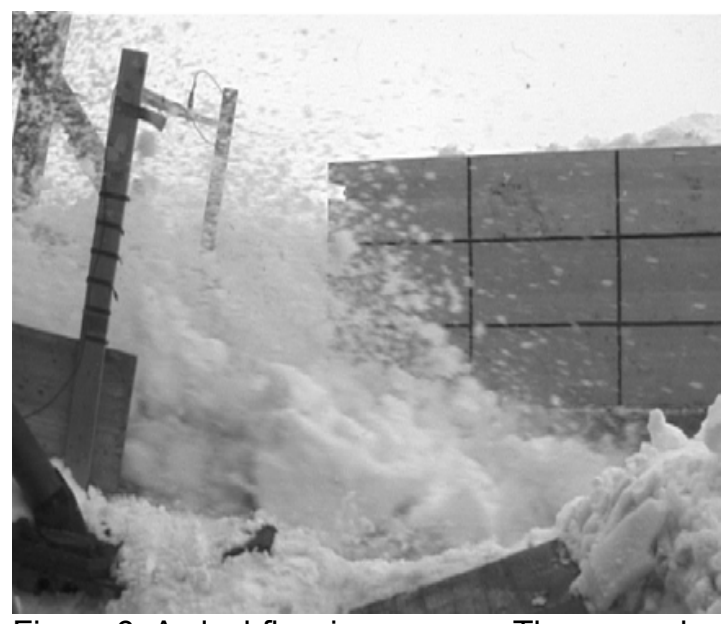

Figure 6: A slushflow in progress. The second flow height sensor can be seen at bracket over the flow

b) Normal and shear forces on galleries In connection to studies of snow avalanche forces on road and railroad galleries, also experiments with slushflows were carried out. The lowest part of the chute can be lifted, so that gallery roofs of different angles can be simulated.

Two force plates with a sensitive area of $0.46 \mathrm{~m}^{2}$ were installed flush to the chute surface to measure basal normal and shear stresses exerted by the flow. The plates are referred to as plate 1 and 2 or 3 and 4. Plates 1, 2 were replaced with plates 3, 4 which provide higher measurement accuracy.

c) Impact pressure on an obstacle in the flow In principle it is possible to measure avalanche velocities in test sites using pressure cells in the avalanche track. To compute the velocity from the pressure measurements, the drag factor $C_{D}$ and the flow density have to be known. The drag factor is suspected to be highly variable for different snow densities and water contents. To study the drag factor $C_{D}$ in slushflows, a pylon with a pressure cell was installed in the chute.

The water content of the snow used in the experiments, never reached more than approximately $20-30 \%$. At this level, the rate of drainage from the snow (through the voids at the lock of the chute) was approximately equal to the flow rate of water added from the fire hose. All slushflow experiments were performed at the lowest possible inclination of the chute (32 degrees).

\section{RESULTS}

As the experiments were divided into three groups to study velocity profiles, normal and shear forces on galleries and pressure measurements on an obstacle in the flow, the results are divided into three sections accordingly.

To give a first overview, the key numbers of the results of all experiments are listed in Table 2. Velocities range from 6 to $12 \mathrm{~m} \mathrm{~s}^{-1}$ and impact pressures from 42 to $119 \mathrm{kPa}$. The flow heights reached up to 100 $\mathrm{cm}$.

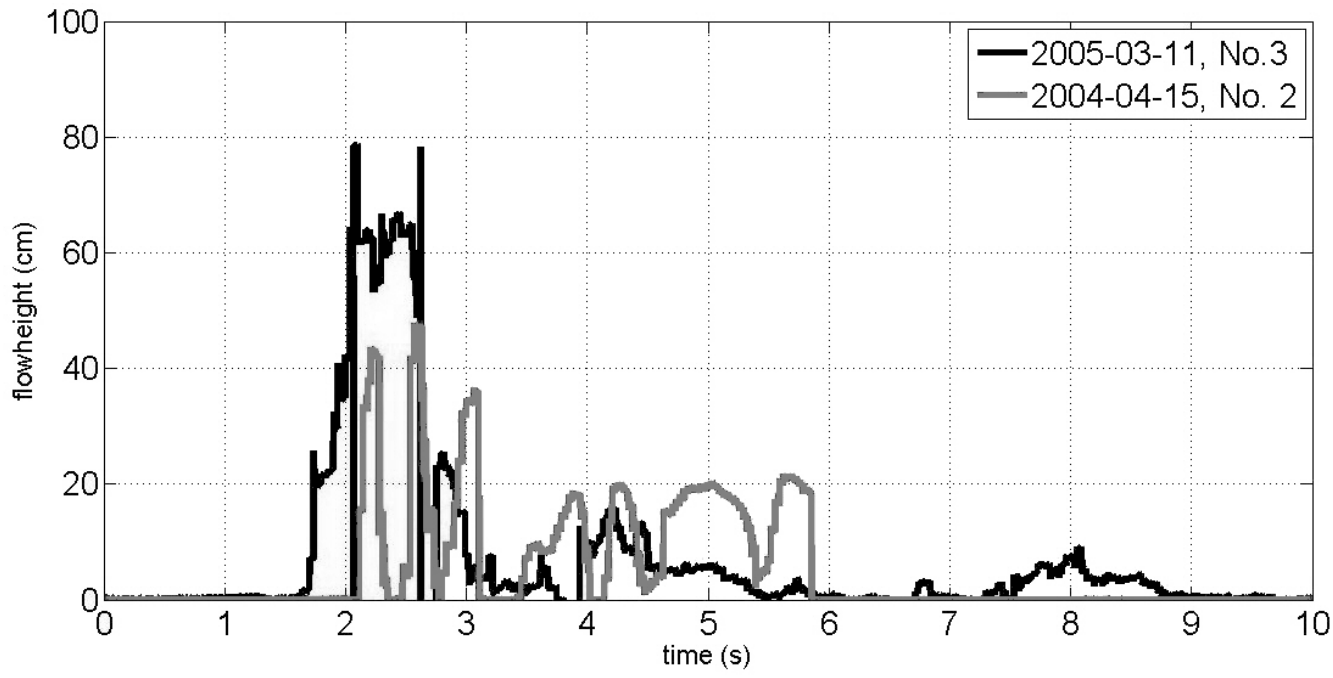

Figure 7: Flow height measurements from a dry snow avalanche (black) and a slushflow (grey) 


\subsection{Velocity measurements and profiles}

Experiments were performed to study the detailed velocity profiles in the lowest $5 \mathrm{~cm}$ of the flow both in slushflows and in snow avalanches. For these experiments, the optical velocity array was installed in centerline of the chute. Figure 4 and Figure 5 show velocity profiles for snow and slush, respectively. The profiles are averaged over the time period indicated in the figure. The velocities reach $7.5 \mathrm{~m} \mathrm{~s}^{-1}$ in snow and $10 \mathrm{~m} \mathrm{~s}^{-1}$ in slush.

The error bars in the figure illustrate the variability of the results. While the data for the snow profiles generally is good and the variability low, the results for the slushflow experiments are much less conclusive. This is most likely caused by different optical properties of snow and slush, which cause blurred signals in the case of slushflows. For a detailed discussion of the measurement problem see Guenther (2006).

\subsection{Flow heights}

The flow height of the slushflows was observed at two locations by ultrasonic distance sensors. During some experiments the range of the instruments was exceeded. This is mainly caused by a well established saltation layer on top of the slushflow. Video observations (Figure 6) show particles as high as two meters above the chute. Figure 7 compares the flow height of a slushflow with the one of a dry snow avalanche. A significant difference in the size and shape of the slides can be observed. While the avalanche moves in a single body, the slushflow appears in distinct surges.

\subsection{Shear and normal stresses}

Shear and normal stresses were recorded in the chute during both snow and slushflow experiments. The data is collected on two load plates that are integrated in the measurement section of the chute. The first plate is located just after the first bend in the second section of the chute. This section is fixed at an inclination of 32 degrees inclination. The second load plate is located

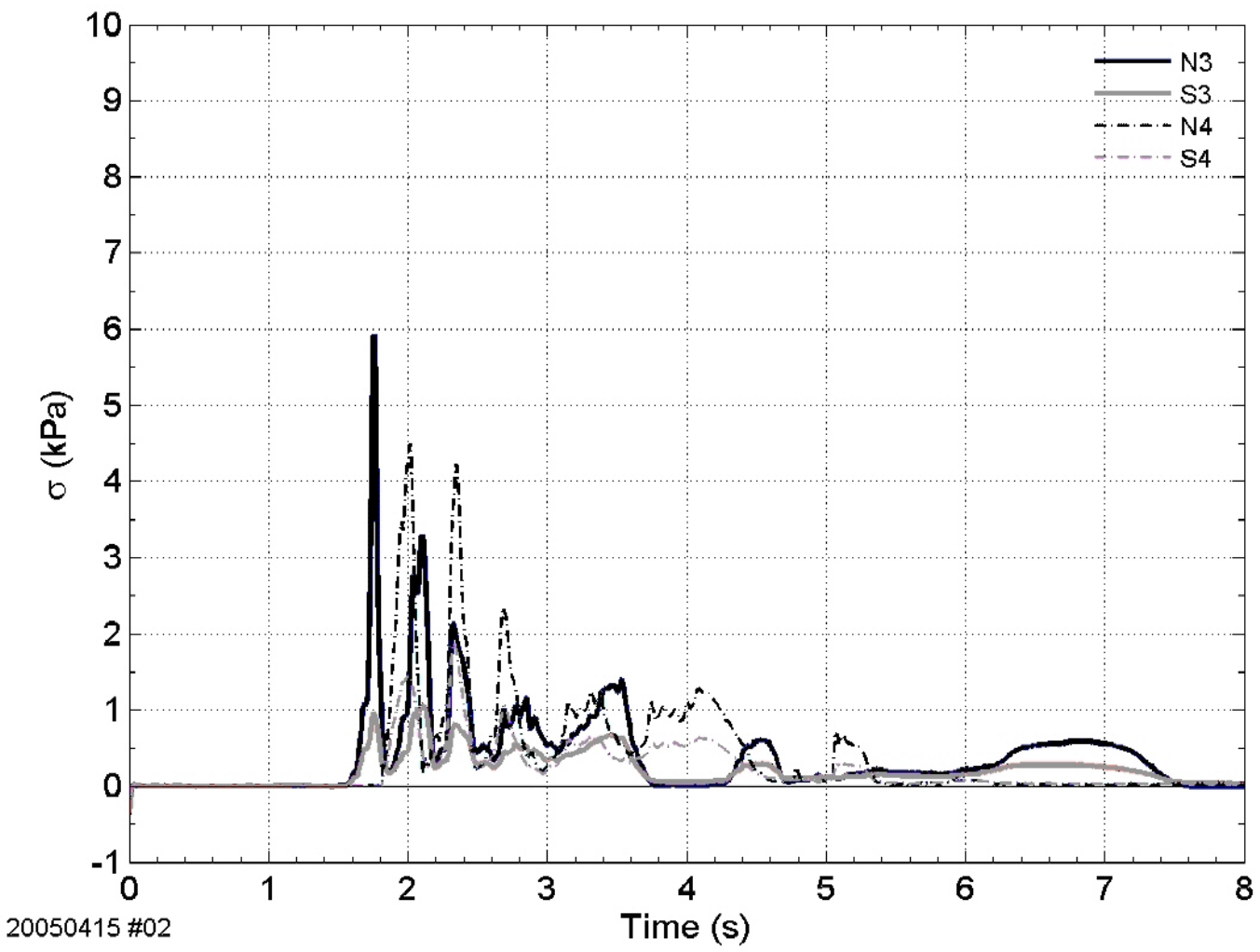

Figure 8: Results from the basal load plates passed by a slushflow (normal and shear stress at plate 3 and 4; plate 4 is located downstream a concave bend of the slope) 
after the second bend to the third section of the chute (Fig. 1). This third section was adjusted to four different angles during the measurements with the force plates (see Table 1 for details on the used angles). The plates measure both normal and shear forces during the slide event. Figure 8 shows results from a slushflow experiment. The normal forces are approximately twice as high as the shear forces. A more thorough analysis of the data including also the results from dry and wet snow was done by Platzer et al. (2006).

\subsection{Pressure cell}

The pressure cell was installed during the experiments to determine the drag coefficient in slushflows. The instrument consisted of a Kistler pressure cell that was preloaded with $10 \mathrm{kPa}$. The pressure cell was mounted on a vertical steel pole and pointed normal to the flow (Figure 2). Four experiments collected useful data. Maximum measured pressure ranged from 50 to $81 \mathrm{kPa}$ (Table 1) The results for experiment 01 on 18 April 2005 is shown in Figure 9 where the highest pressure values correspond well with the arrival of the first slush front at the pressure cell. The combination of velocity and pressure measurements allows an estimation of the drag factor $C_{D}$.

\subsection{Video observations}

Video observations were made on a regular basis. Different angles were chosen for different experiments. The videos allow to determine (Fig. 6) interesting features, such as the structure of the avalanches as well as the flow height and the kind of movement (block or turbulent).

\section{DISCUSSION}

The experiments at the SLF chute were a first test of the applicability of available equipment in slushflow studies. Generally, the instrumentation and physical setup of the chute is well suited for such experiments, except of its steepness:

Slushflows are observed in rather flat terrain in nature down to an inclination of only a few degrees. The experiments at the chute were all on a 32 degree
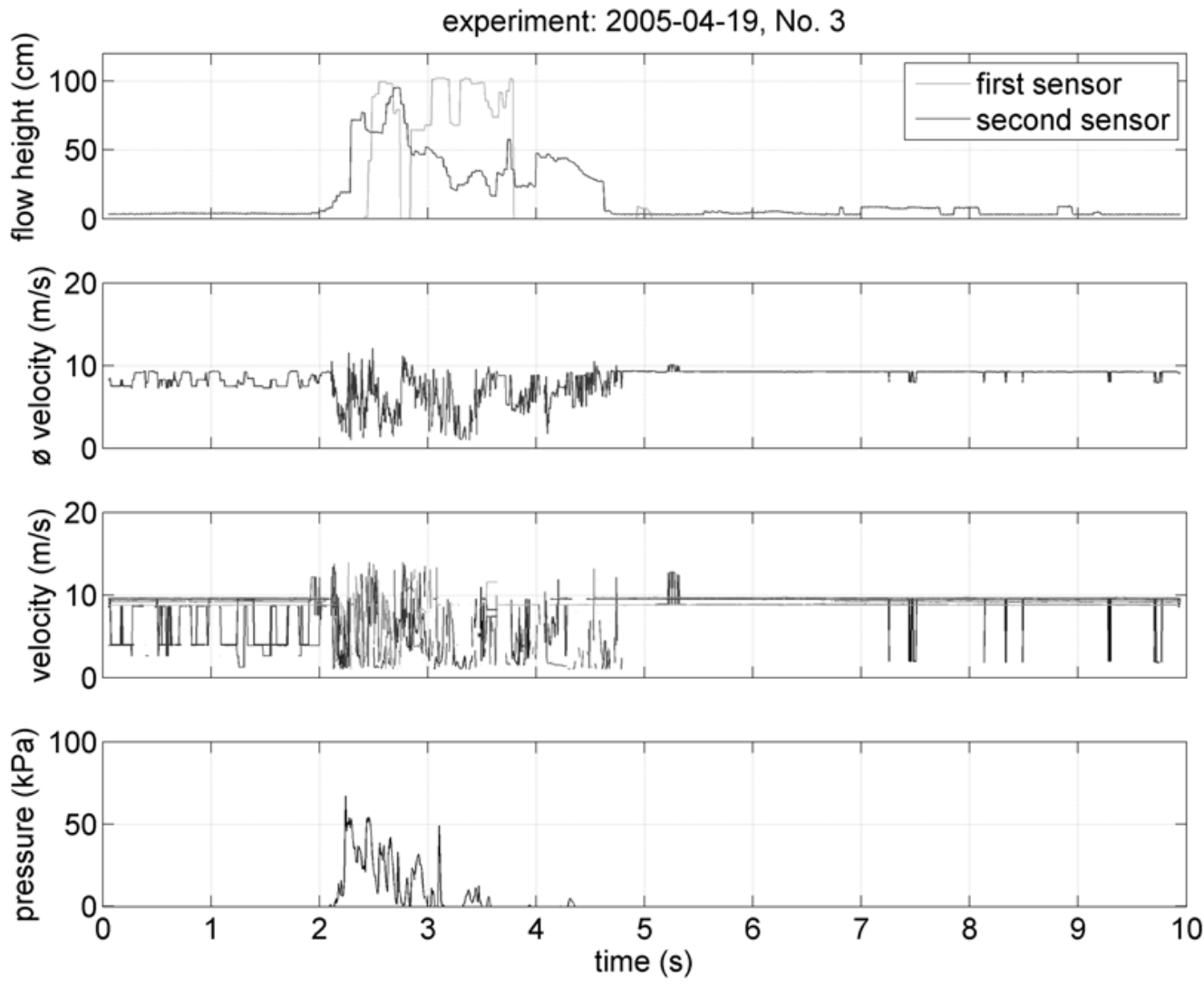

Figure 9: Time series of a slushflow experiment on the pressure cell 
inclination, which is rather steep in this context. It would be desirable to do similar studies on lower inclinations as well. The advantage with the 32 degrees at the chute is the fast development of a turbulent flow down the chute. However, it limits the initial water content.

The applied instruments proved to be reliable and resistant against a rough environment. Since one of the major objectives of this project was the test of available instrumentation, a more detailed discussion of the instruments is given below.

\subsection{Optical velocity measurements}

The flow velocities are measured with optical velocity sensors (Tiefenbacher and Kern, 2004). To achieve a good signal to noise ratio the contrast between the particles and the surrounding material must be as large as possible. For the study of snow, LEDs with infrared light were applied. These give good results for snow, but have difficulties in identifying particles in slush. This might be an explanation for the fact that the slushflow experiments produced spiky and unreliable results. Only a few data points could be used for the analysis of the velocity profiles and also the calculation of the drag coefficient is strongly influenced by the limited performance of the velocity measurements.

It is suggested to improve the design of the instruments when used in slushflow experiments. A change in the applied wave length from infrared to higher ones may improve the results significantly. A first prototype to test this approach is currently developed at the SLF to be tested next winter (Guenther, 2006).

\subsection{Ultrasonic flow height measurements}

The flow height is measured by ultrasonic sensors. The largest problem with these instruments is the uncertainty of where the actual measurement surface is located in a highly turbulent flow. The instrument will detect the distance to the closest particle of a certain dimension rather than giving an average flow height of the avalanche. The results from the measurements give a valuable impression of the size and structure of the slide in the chute. There is no significant difference in the performance of the instruments in snow or slush experiments.

\subsection{Normal and shear stress measurements}

Normal and shear stresses were recorded on two load plates along the chute. Both plates are installed flush with the chute surface. In comparison with snow experiments, the instruments performed well also during slushflow experiments. The results showed some interesting differences in the forces exerted by the two types of slides. While snow avalanches move like one continuous body, the slushflows move in surges of distinct parts.

\section{$5.4 \underline{\text { Pressure cells }}$}

The traditional standard instruments for the estimation of avalanche velocities are pressure cells installed normal to the flow. These instruments have been widely used in instrumented avalanche paths both in Europe and America. The instruments record only the pressure on the load cell during the passage of the avalanche. For the estimation of the velocity, the density of the avalanche and the drag factor have to be known.

The chute experiments give the unique possibility of combined velocity and pressure measurements. The pressure cell is the same type as installed, e.g., at the Vallée de la Sionne experimental site. The range of the instruments was adjusted to the expected pressures at the chute.

The instruments delivered reliable and valuable results. Only the signal to noise ratio should be improved for increased performance.

\section{$5.5 \underline{\text { Video observations }}$}

The use of video recordings for the documentation of the experiments is very valuable. The experiments are extremely short and it is difficult for the observer to study the movement during the experiment itself. The use of manually operated video cameras has many disadvantages such as changing angles from one experiment to another as well as limited frame quality. Instead a group of 2-4 permanent video cameras should be available, controlled by the central data acquisition system, such that the time scale is equal for all observations. Such a system would allow the application of photometric analysis of the pictures for a second estimate of the flow velocity and the flow height of the slide. 


\section{CONCLUSION AND OUTLOOK}

The small scale experiments on slushflows were a major success. The results show that such experiments are possible at the Weissfluhjoch snow chute. The instruments showed in an impressive way the forces and destructive potential of slushflows. Comparison of normal and shear forces of dry snow avalanches and slushflows clearly indicates that slushflows cause high stresses on the surface and structures. It is obvious that slushflows need to be considered in the design criteria of protection measures wherever they can occur.

In many ways, the experiments have to be considered as a first try. One of the objectives was to test different instrumentation for their applicability in slushflow experiments. Most of the instruments worked well in slush. Only the optical velocity sensors have to be redesigned to give better results for slush.

A large amount of data was collected during this season, both for avalanches and slushflows. The major objective of this contribution was a mere documentation of the work achieved and a short discussion of the instruments and facilities. A more detailed analysis of the data will give interesting information on the feasibility of full scale slushflow experiments and is left to future publications.

\section{ACKNOWLEDGEMENTS}

The experiments were made possible by a joint project financed by the Norwegian Research Council, The Norwegian Geo-technical Institute research fund and the SLF. The work intensive experiments were only possible by the physical help and psychological support of many persons at the SLF.

\section{REFERENCES}

Bozhinskiy, A.N, Nazarov, N.N, 1998. Dynamics of two-layer slushflows. In Hestens, E., editor, 25 Years of Snow Avalanche Research, Volume 203 of $\mathrm{NGI}$-Publication. Oslo, Norwegian Geotechnical Institute, pp. 74-78.

CFX-4.3 Flow Solver User Guide (1999): ANSYS

Gauer, P, 2003. SIP8 Offshore Geohazards, Feasibility study for a slushflow model within CFX4. NGI Report 20021023̃35, Norwegian Geotechnical Institute, Oslo.

Gauer, P, 2004. Numerical Modeling of a Slushflow Event. submitted to Proceedings of the International Snow Science Workshop 2004, Jackson Hole, Wyoming, United States.

Gauer, P, Issler, D, Lied, K, Kristensen, K, Iwe, H, Lied, E, Rammer, L, Schreiber, H, in press. On full-scale avalanche measurements at the Ryggfonn test site, Norway. Cold Region Science and Technology

Guenther, G, 2006. Developement of an optical sensor for flow velocities in slushflows Technical report, SLF Davos (in German)

Hestnes, E, 1985. A contribution to the prediction of slush avalanches. Annals of glaciology, 6, 1-4.

Hestnes, E, Bakkehøi, S, Sandersen, F, Andresen, L. 1994. Weather and snow pack conditions essential to slushflow release and down slope propagation. International Snow Science Workshop, 1994, Snowbird, Utah, USA, 40-57.

Onesti, L.J, 1985. Meteorological conditions that initiate slushflows in the central brooks range, Alaska. Annals of glaciology, 6, 23-25.

Onesti, L.J., Hestners, E, 1989. Slush-flow questionnaire. Annals of glaciology, 13, 226-230.

Platzer, K, Bartelt, P, Jaedicke, C, 2006. Basal shear and normal stresses of dry and wet snow avalanches after a slope deviation. Submitted to Cold Regions Science and Technology.

Scherer, D, Gude, M, Gempler, M, Parlow, E 1998. Atmospheric and hydrological boundary conditions for slushflow initiation due to snowmelt. Annals of glaciology, 26, 377-380.

Scherer, D, Groebke, L, Parlow, E, 2001. Photogrammetric analysis of a slush torrent in the Kæekevagge, Northern Sweden. Nordic Hydrology, 385-393

Sovilla, B, Schaer, M, Kern, M, Bartelt, P, 2006. Impact pressures and flow regimes in dense flow avalanches observed at the Vallée de la Sionne test site. submitted to Journal of Geophysical Research

Tiefenbacher F, Kern, M, 2004. Experimental devices to determine snow avalanche basal friction and velocities profiles. Cold Regions Science and Technology, 38, 17-30. 